\title{
Regeneration of kidney tissue using in vitro cultured fetal kidney cells
}

\author{
Sang-Soo Kim ${ }^{1,2}$, So-Jung Gwak ${ }^{3}$, Joungho $\mathrm{Han}^{4}$, \\ Moon Hyang Park ${ }^{5}$, Kang Won Song ${ }^{5}$ \\ and Byung-Soo Kim ${ }^{1,6}$ \\ ${ }^{1}$ Department of Bioengineering \\ Hanyang University \\ Seoul 133-791, Korea \\ ${ }^{2}$ Immune Disease Institute \\ Harvard Medical School \\ Boston, MA 02115, USA \\ ${ }^{3}$ Department of Chemical Engineering \\ Hanyang University \\ Seoul 133-791, Korea \\ ${ }^{4}$ Department of Pathology \\ Samsung Medical Center \\ School of Medicine, Sungkyunkwan University \\ Seoul 135-710, Korea \\ ${ }^{5}$ Department of Pathology \\ College of Medicine, Hanyang University \\ Seoul 133-791, Korea \\ ${ }^{6}$ Corresponding author: Tel, 82-2-2220-0491; \\ Fax, 82-2-2291-0838; E-mail, bskim@ hanyang.ac.kr \\ DOI 10.3858/emm.2008.40.4.361
}

\section{Accepted 3 April 2008}

Abbreviations: CFU, colony forming unit; FKC, fetal kidney cells; PCNA, proliferating cell nuclear antigen; SA- $\beta$-gal, senescenceassociated $\beta$-galactosidase

\footnotetext{
Abstract

Transplanting fetal kidney cells (FKCs) can regenerate kidney. This requires in vitro expansion in cell number to acquire enough cells for transplantation. However, FKCs may change their cellular characteristics during expansion and, thus, may not regenerate kidney tissue upon transplantation. We investigated how cell culture period affects cellular characteristics and in vivo regenerative potential of FKCs. As the passage number increased, cell growth rate and colony forming ability decreased while senescence and apoptosis increased. To examine in vivo regenerative potential, FKCs cultured through different numbers of passages were implanted into the parenchyma of kidneys of immunodeficient mice using fibrin gel for $4 \mathrm{wk}$. Histological analyses showed passage-dependent kidney tis-
}

sue regeneration, and the regeneration was better when cells from lower number of passages were implanted. This result shows that in vitro culture of FKCs significantly affects the cell characteristics and in vivo tissue regenerative potential.

Keywords: apoptosis; cell aging; cell proliferation; cell transplantation; fetal stem cells; kidney; tissue engineering

\section{Introduction}

An alternative therapeutic approach for the treatment of devastating end-stage renal disease under recent investigation is stem cell therapy (Hammerman 2004; Steer and Nigam, 2004). Recently, the transplantation of kidney precursor tissues (metanephroi), isolated from early human, porcine, and murine embryos has been investigated and resulted in the partial restoration of kidney structure and function (Hammerman, 2000; Dekel et al., 2003). In another study, therapeutically cloned kidney cells were cultured in vitro and transplanted with polymer scaffolds into the nuclear donor animals. The transplanted cells regenerated glomerulus-like and tubule-like structures and excreted urine-like fluid in vivo (Lanza et al., 2002). Previously, we have conducted a study on the reconstruction of kidney structures by transplantation of fetal kidney cells (FKCs) freshly isolated from metanephroi of rat fetuses using three-dimensional biodegradable polymer scaffolds (Kim et al., 2005; 2007a,b).

Transplantation of freshly isolated FKCs without cell expansion may require the sacrifice of many fetuses in order to obtain a sufficient number of cells to transplant. Therefore, in vitro expansion of FKCs isolated from a small biopsy would be a better means for obtaining a large number of cells for kidney regeneration by cell transplantation. However, the in vitro culture period may affect the cellular characteristics and the ability of FKCs to regenerate kidney tissue upon transplantation.

The objective of this study was to investigate the effects of culture passage of FKCs on their in vitro cellular characteristics and on in vivo regenerative potentials. FKCs were isolated from metanephroi and cultured through passage zero (P0), one (P1), and two (P2) times, and cellular characteristics were examined. FKCs cultured through differing 
numbers of passages were transplanted into the parenchyma of kidneys of immunodeficient mice, and kidney tissue regeneration was examined histologically.

\section{Materials and Methods}

\section{Isolation and culture of FKCs}

FKCs were isolated from rat fetuses on day 17.5 of gestation, as previously described (Kim et al., 2005). In brief, metanephroi were surgically dissected from the fetuses of Sprague-Dawley rats (SLC, Tokyo, Japan) and washed with Hank's balanced salt solution (HBSS, Gibco BRL, Grand Island, NY). Metanephroi were minced into small pieces and digested in collagenase/dispase solution (1 $\mathrm{mg} / \mathrm{ml}$, Roche, Indianapolis, IN) at $37^{\circ} \mathrm{C}$ for 30 min (Lanza et al, 2002; Kim et al., 2005). Isolated cells were strained through a $40 \mu \mathrm{m}$ nylon mesh (Becton Dickinson, Franklin Lakes, NJ) and collected by centrifugation. Collected FKCs were plated at $1.25 \times 10^{5}$ cells per well of a six-well dish and cultured in DMEM (Gibco BRL) containing $10 \%$ (v/v) FBS (Gibco BRL) or in keratinocyte serum free medium (KSFM, Gibco BRL), containing $2 \%(\mathrm{v} / \mathrm{v})$ FBS and ITS liquid media supplement (Sigma, St. Louis, MO) in a humidified $5 \% \mathrm{CO}_{2}$ incubator (Yoo et al., 1996). The kidney is composed of over 30 different cell types and it is difficult to ensure the cell culture condition for all cell types. Therefore, we have used two different cell culture conditions; culture in DMEM containing $10 \%$ (v/v) FBS (high serum concentration) for kidney stromallike cells and culture in KSFM containing $2 \%(\mathrm{v} / \mathrm{v})$ FBS and ITS (low serum concentration) for kidney epithelial-like cells. Six days after plating, the cells were sub- cultured with $0.05 \%(\mathrm{w} / \mathrm{v})$ trypsin/EDTA (Sigma) at a density of $1.25 \times 10^{5}$ cells per well of a six-well dish. The numbers of cells cultured in both culture conditions were determined using a trypan blue exclusion assay.

\section{TUNEL assay}

On day 6 of culture, TUNEL assay was performed to detect cell death-related DNA cleavage in the cultured FKCs using an ApopTag kit (Chemicon, Temecula, CA) according to manufacturer's instructions. Stained cells were examined with a confocal microscope (Fluoview BX50, Olympus, Tokyo, Japan).

\section{Senescence-associated $\beta$-galactosidase (SA- $\beta$-gal) staining}

Senescent FKCs were detected by SA- $\beta$-gal staining on day 6 of culture (Dimri et al., 1995). Briefly, the cells cultured on chamber slides were fixed with $2 \%(\mathrm{v} / \mathrm{v})$ formaldehyde $/ 0.2 \%(\mathrm{v} / \mathrm{v})$ glutaraldehyde for $5 \mathrm{~min}$. The cells were then washed twice with PBS and incubated with SA- $\beta$-gal staining solution [1 $\mathrm{mg} / \mathrm{ml}$ 5-bromo-4-chloro-3-inolyl-b-d-galactoside in dimethyformamide, $5 \mathrm{mM}$ potassium ferrocyanide, $5 \mathrm{mM}$ potassium ferricyanide, $150 \mathrm{mM} \mathrm{NaCl}$, $2 \mathrm{mM} \mathrm{MgCl}$, and $40 \mathrm{mM}$ citric acid/sodium phosphate, $\mathrm{pH} 6.0$ (all reagents were purchased from Sigma)] at $37^{\circ} \mathrm{C}$ for $18 \mathrm{~h}$. The cells were photographed, and the percentage of stained cells was counted in ten fields at $400 \times$ magnification using an optical microscope.

\section{RT-PCR}

Total RNA was isolated from cultured FKCs in triplicate, using an RNeasy Mini kit (Qiagen $\mathrm{GmbH}$, Hilden, Germany), and first-strand cDNA was synthesized from $5 \mu \mathrm{g}$ of total RNA with SuperScript II reverse transcriptase (Invitrogen, Carlsbad, CA). Synthesized cDNA was amplified with a thermal cycler (GeneAmp PCR System 2700, Applied Biosystems, Foster City, CA), using primers for Bax, $\mathrm{Bcl}-2$, p16 ${ }^{\text {INK4a }}$, and GAPDH. The rat GAPDH was used as an internal control for template amount adjustment. The primers specific for rat $\mathrm{p} 16^{\text {INK4a }}$ were: 5'-AACACTTTCGGTCGTACCC-3' (forward) and 5'-GTCCTCGCAGTTCGAATC-3' (reverse) (Melik et al., 2003). Primers specific for Bax, Bcl-2, and GAPDH were used from commercially available kits (Apoptosis PCR Bax/Bcl-2 Multiplex Primer Sets, Sigma). PCR was performed for 30 cycles of denaturing $\left(94^{\circ} \mathrm{C}, 30 \mathrm{~s}\right)$, annealing $\left(55^{\circ} \mathrm{C}, 60 \mathrm{~s}\right)$, and extension $\left(72^{\circ} \mathrm{C}, 45 \mathrm{~s}\right)$, with a final extension at $72^{\circ} \mathrm{C}$ for $7 \mathrm{~min}$. The PCR products were visualized by electrophoresis on $2 \%(\mathrm{w} / \mathrm{v})$ agarose gels, containing $0.5 \mu \mathrm{g} / \mathrm{ml}$ ethidium bromide.

\section{Colony forming unit assay}

In order to measure colony forming units (CFU), cells were plated in triplicate on gridded $35-\mathrm{mm}$ culture dishes (Nunc, Naperville, IL) at a density of $5 \times 10^{4}$ cells/dish and cultured in standard culture medium, composed of an equal volume mixture of $18 \%(\mathrm{w} / \mathrm{v})$ methylcellulose solution (Sigma) and $2 \times$ concentrated DMEM, with $20 \%$ FBS or $2 \times$ concentrated KSFM. Cells were incubated for two wk under fully humidified conditions in an atmosphere of $5 \% \mathrm{CO}_{2}$ at $37^{\circ} \mathrm{C}(\mathrm{Kim}, 1998)$. Colonies of greater than fifty cells were counted under a stereomicroscope and the CFU per $5 \times 10^{4}$ cells were calculated. 
A
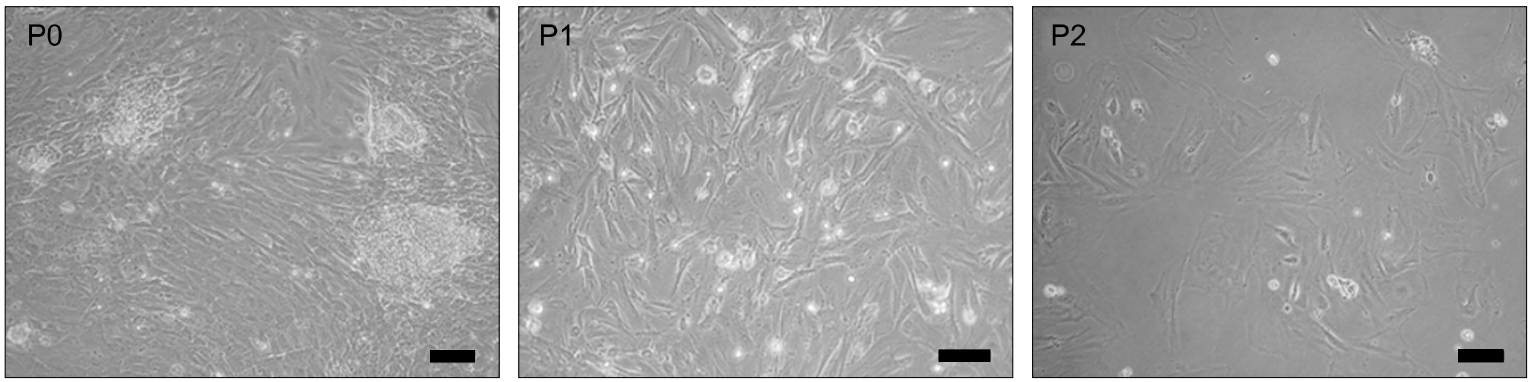

B
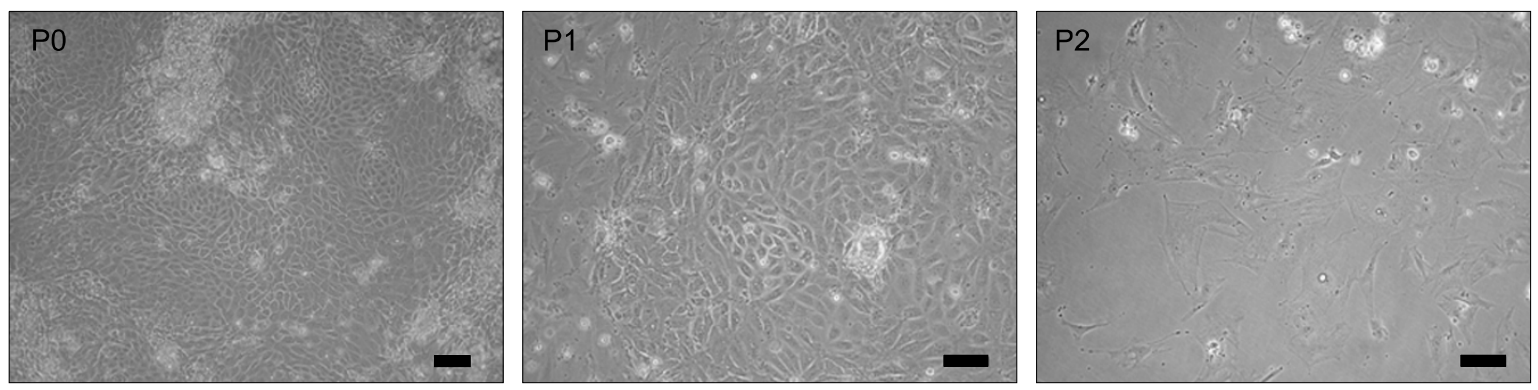

Figure 1. Cellular appearance of cultured fetal kidney cells. (A) Fetal kidney cells cultured in DMEM with $10 \%$ (v/v) FBS show spindle-shaped and polygonal morphology, whereas (B) fetal kidney cells cultured in KSFM with 2\% (v/v) FBS and ITS show cobblestone-like morphology. The scale bars indicate $20 \mu \mathrm{m}$.

\section{Cell labeling}

Prior to cell transplantation, FKCs were fluorescently labeled with CM-Dil Cell Tracker (Molecular Probes, Eugene, OR), which incorporates into cellular membranes. Harvested FKCs were washed twice with HBSS and incubated with HBSS, containing CM-Dil $2 \mu \mathrm{g} / \mathrm{ml}$ for $5 \mathrm{~min}$ at $37^{\circ} \mathrm{C}$, then for an additional $15 \mathrm{~min}$ at $4^{\circ} \mathrm{C}$, according to the supplier's staining protocol (Jeong et al., 2004; Deng et al., 2005). After labeling, cells were washed three times with PBS, resuspended in fresh medium, and mixed with fibrin gel scaffolds for cell transplantation.

\section{Transplantation of FKCs into the renal parenchyma of immunodeficient mice}

A fibrin gel was utilized as a three-dimensional scaffold to transplant FKCs into the renal parenchyma immunodeficient mice (BALB/c-nu, 7 wk-old females, SLC, Tokyo, Japan). The fibrin gel was prepared from a commercially available fibrin kit (Greenplast, Greencross PD Co., Yongin, Korea) (Ryu et al., 2005). We have used fetal kidney cells cultured in both culture conditions [DMEM containing $10 \%$ FBS (high serum concentration) and KSFM containing $2 \%$ FBS and ITS (low serum concentration)] together for implantation. After in vitro expansion using two different culture conditions, same amount of fetal kidney cells from both condition were mixed together and resuspended in solutions of thrombin $(0.5 \mathrm{ml})$ and fibrinogen $(0.5$ $\mathrm{ml}$ ) to the density of $6.0 \times 10^{7}$ cells $/ \mathrm{ml}$. After mice were anesthetized with an intramuscular administration of ketamine hydrochloride $(50 \mathrm{mg} / \mathrm{kg}$, Yuhan Co., Seoul, Korea) and xylazine hydrochloride (5 $\mathrm{mg} / \mathrm{kg}$, Bayer Korea Ltd., Seoul, Korea), the kidney was exposed by a midline laparotomy. Through a device designed for simultaneous injection of the fibrinogen and thrombin solutions, $0.05 \mathrm{ml}$ of the fibrin mixture containing FKCs $\left(3.0 \times 10^{6}\right.$ cells $)$ was injected into the parenchyma of the left kidney of immunodeficient mice $(n=5)$. The grafts were retrieved for analyses $4 \mathrm{wk}$ after transplantation.

\section{Histological and immunohistochemical analyses}

For histological analyses, retrieved implants were fixed in $10 \%(\mathrm{v} / \mathrm{v})$ buffered formalin, dehydrated with graded ethanol, and embedded in paraffin. 5 $\mu \mathrm{m}$-thick tissue sections were processed for hematoxylin and eosin (H\&E) staining. Glomeruli were counted under a microscope. For immunohistochemical analyses, $5 \mu \mathrm{m}$-thick sections were stained with antibodies against proliferating cell nuclear antigen (PCNA, DAKO, Carpinteria, CA) (Kim et al., 2006). The staining signals were developed, using a streptavidin biotin universal detection system (UltraTech HRP, Immunotech, Marseille, France) and 3,3'-diaminobenzidine tetrahydrochloride substrate solution (Vector Lab). 


\section{Fluorescence microscopy}

Five $\mu \mathrm{m}$-thick tissue sections were analyzed for CM-Dil labeling (red fluorescence) under a fluorescence microscope (Eclipse E800, Nikon, Garden City, NY) 4 wk after transplantation into the kidneys of immunodeficient mice.

\section{Statistical analyses}

Quantitative data are expressed as the mean \pm SD. Statistical comparisons were carried out, using ANOVA (SAS Institute Inc., Cary, NC). The data were considered statistically significant if the $P$ values were less than 0.05

\section{Results}

\section{Proliferative and colony formation ability of FKCs}

A

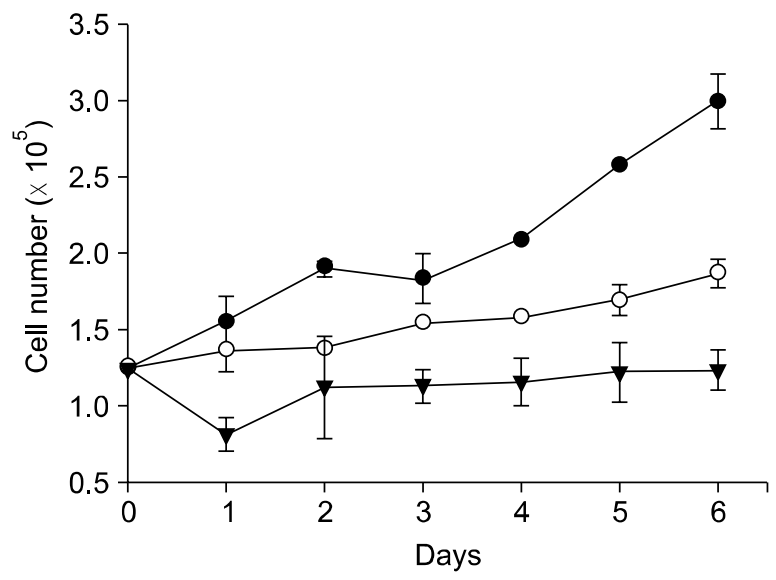

C

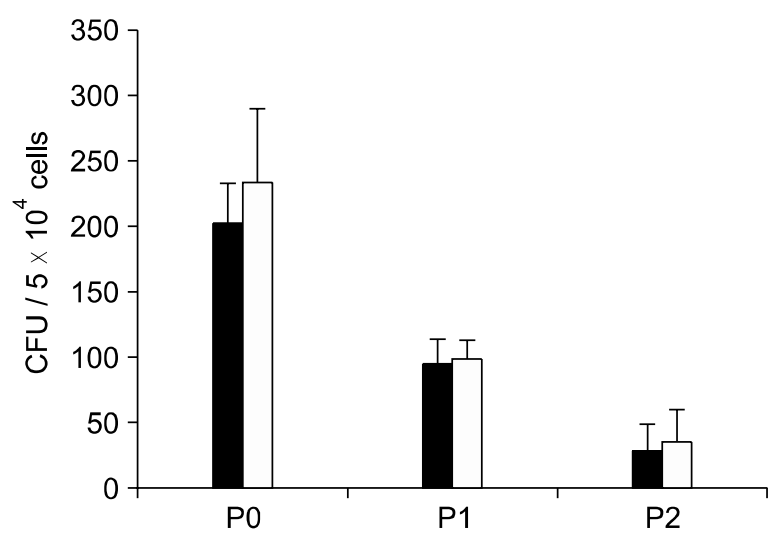

FKCs, cultured in DMEM with $10 \%(\mathrm{v} / \mathrm{v}) \mathrm{FBS}$, showed spindle-shaped and polygonal morphology, whereas FKCs cultured in KSFM showed cobblestonelike morphology (Figure 1). The passage number of FKCs affected the cell growth rate in monolayer culture. As the passage number increased, the cell growth rate decreased dramatically for both types of cells (Figure 2A and $\mathrm{B}$ ). Unpassaged ( $\mathrm{PO}$ ) and one-time-passaged (P1) cells continued to proliferate over a six-day culture period, but the proliferation rate decreased with increasing passage number. The number of $\mathrm{P} 0$ and $\mathrm{P} 1$ cells increased by $2.4 \pm 0.1$ and $1.5 \pm 0.1$ fold when cultured in DMEM with $10 \%(\mathrm{v} / \mathrm{v}) \mathrm{FBS}$, and $4.2 \pm 0.1$ and 2.6 \pm 0.1 fold in KSFM over a 6-day culture period. However, twice-passaged (P2) cells grew very little in number in both types of cultures. The colony formation ability was highest in the PO cells and gradually decreased with increasing passage number in both types of culture (Figure 2C).

B

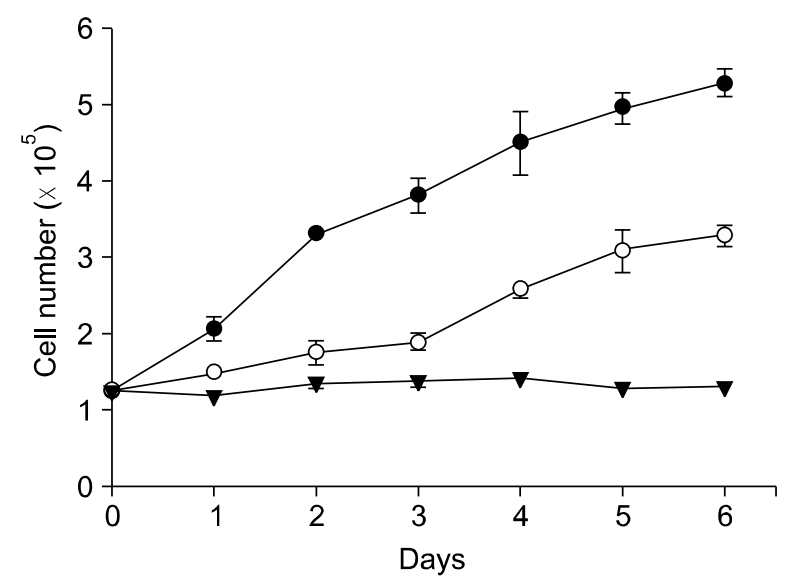

Figure 2. Growth of P0- (solid circles), P1- (open circles), and P2- (solid triangles) FKCs cultured in (A) DMEM and (B) KSFM. $P<0.05$ between any two groups after day 3. (C) Colony formation ability of FKCs cultured in DMEM (solid bars) and KSFM (open bars). 


\section{Apoptotic activity of FKCs}

The apoptotic activity of the cells significantly increased as the passage number increased (Figure 3). On day 6 of culture, apoptotic cells were rare in $\mathrm{PO}$ dishes but increased continuously as the passage number increased in both types of cultures when examined with TUNEL staining. The average ratios of apoptotic cells to P0 cells were $6.5 \pm$ $1.5 \%$ when cultured in DMEM with $10 \%$ (v/v) FBS and $4.5 \pm 0.9 \%$ when cultured in KSFM. However, the average ratios of apoptotic cells for $\mathrm{P} 1$ and $\mathrm{P} 2$ cells increased dramatically to $30.7 \pm 5.9 \%$ and $71.4 \pm 6.0 \%$ when cultured in DMEM and $26.3 \pm$
$8.1 \%$ and $60.9 \pm 11.2 \%$ when cultured in KSFM (Figure 3C). When mRNA levels of apoptosis-related genes were examined with RT-PCR, expression of Bax, a pro-apoptotic gene, was found to continuously increase as the passage number increased (Figure $3 \mathrm{D})$. In contrast, the mRNA levels of $\mathrm{Bcl}-2$, an anti-apoptotic gene, decreased in P1 and P2 as the passage number increased.

\section{Senescence of FKCs}

SA- $\beta$-gal is an indicator of cellular senescence in aging rat kidneys (Yoo et al., 1996). The number of
A

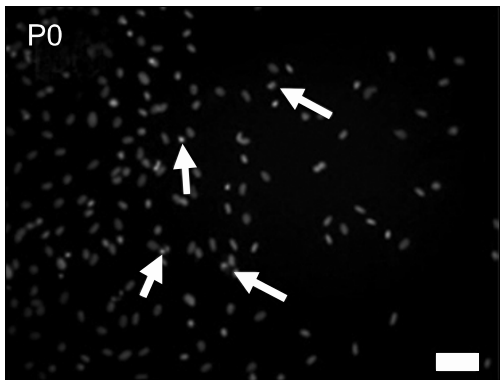

B

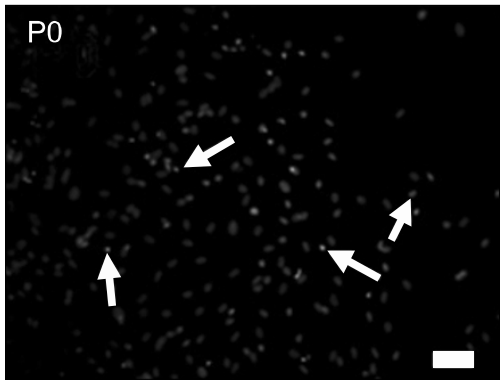

C

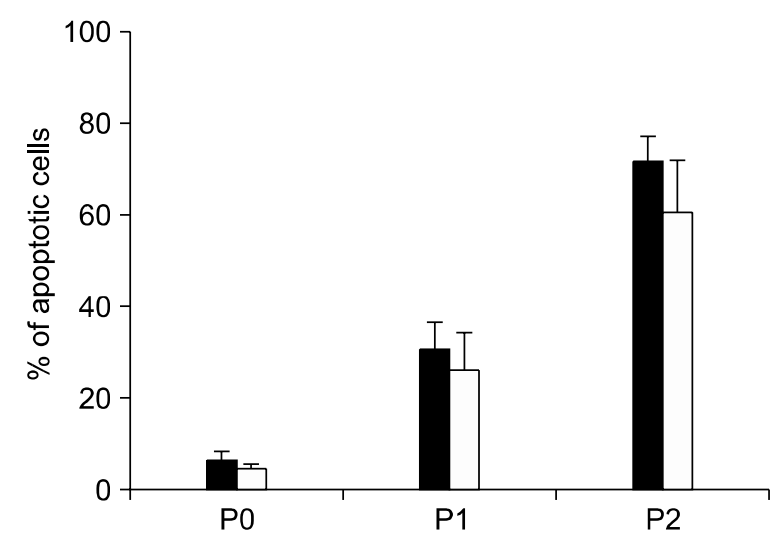

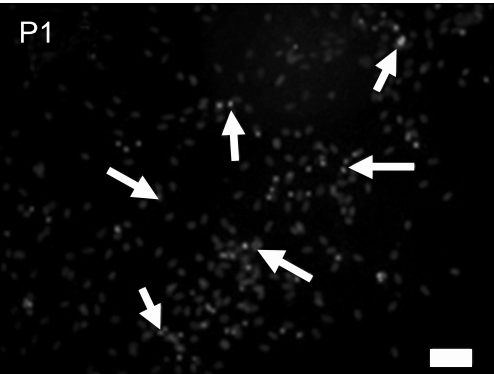
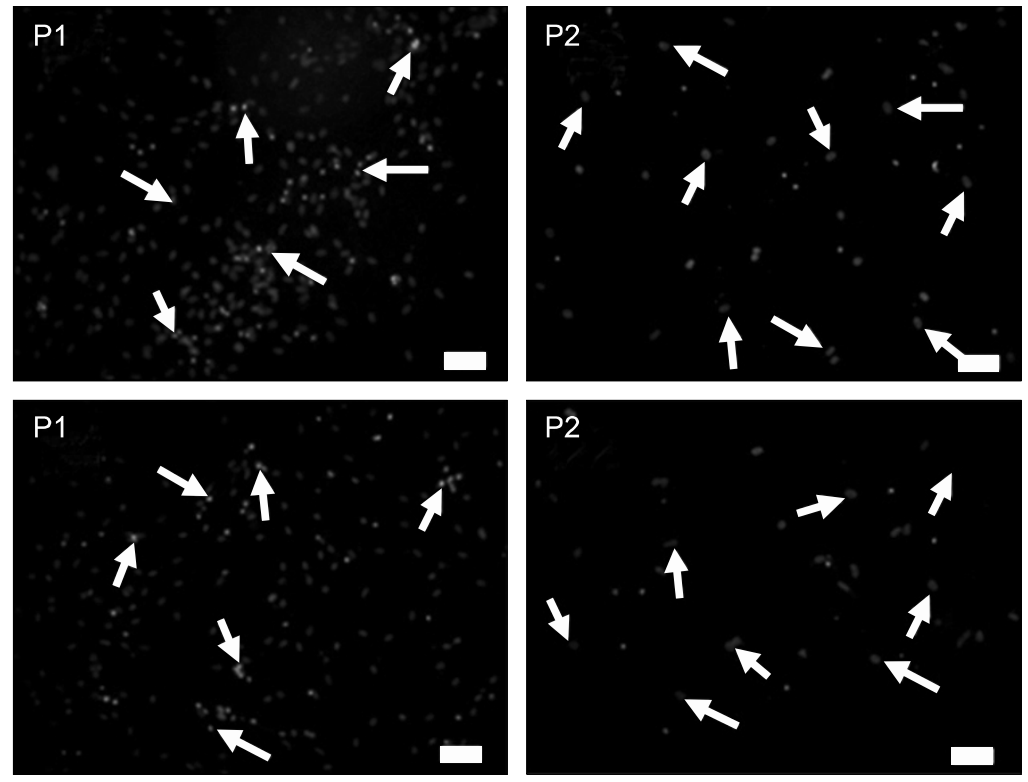

D

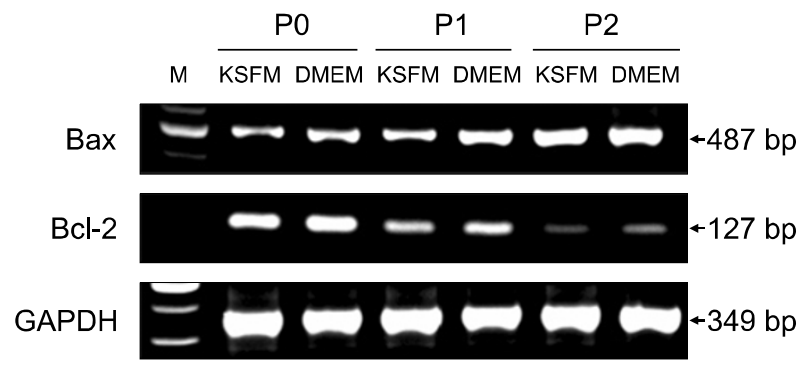

Figure 3. TUNEL staining of FKCs cultured in (A) DMEM and (B) KSFM. The red fluorescence indicates TUNEL-positive apoptotic cells, and the blue fluorescence indicates a cell nucleus. Arrows indicate TUNEL-positive cells. Scale bars indicate $25 \mu \mathrm{m}$. (C) Percent of apoptotic cells in FKCs cultured in DMEM (solid bars) and KSFM (open bars). $P<0.05$ between any two groups. (D) mRNA expression levels of the apoptosis-related genes, Bax and Bcl-2, in cultured FKCs . M: 100 bp DNA molecular weight marker. 
SA- $\beta$-gal- positive cells increased as the passage number increased for both types of cultures (Figure 4A and B). SA- $\beta$-gal-positive cells were detected in less than $5 \%$ in P0 cells (Figure $4 C$ ), and strong SA- $\beta$-gal staining was more prevalent in P2 cells $(59.7 \pm 13.7 \%$ in DMEM and $54.6 \pm$ $13.4 \%$ in KSFM) than in P1 cells $(32.1 \pm 4.7 \%$ in DMEM and $28.8 \pm 4.2 \%$ in KSFM). When the mRNA levels of $\mathrm{p} 16^{\text {INK4a }}$, a specific marker gene for cellular senescence, were examined with RT-PCR, p16 ${ }^{\text {INK4a }}$ expression was found to be very low in PO FKCs in both types of cultures (Figure 4D). However, p16 ${ }^{\text {INK4a }}$ expression was increased in P1 and P2 cells as the passage number increased in both types of cultures. The highest $\mathrm{p} 16^{\text {INK4a }}$ mRNA expression levels were found in the P2 cells.

\section{Reconstitution of kidney tissues by FKC transplantation}

The transplantation of PO FKCs resulted in a reconstitution of kidney structures, including glomeruli and tubules, four weeks after transplantation (Figure 5A and B). Histological examination of retrieved transplants showed distinguishable reconstituted regions between the normal regions of the kidney (Figure 5A). In the reconstituted region, newly formed tubular and glomerular structures were observed (Figure 5B). Newly formed glomeruli were structurally similar to normal glomeruli. In P1

A
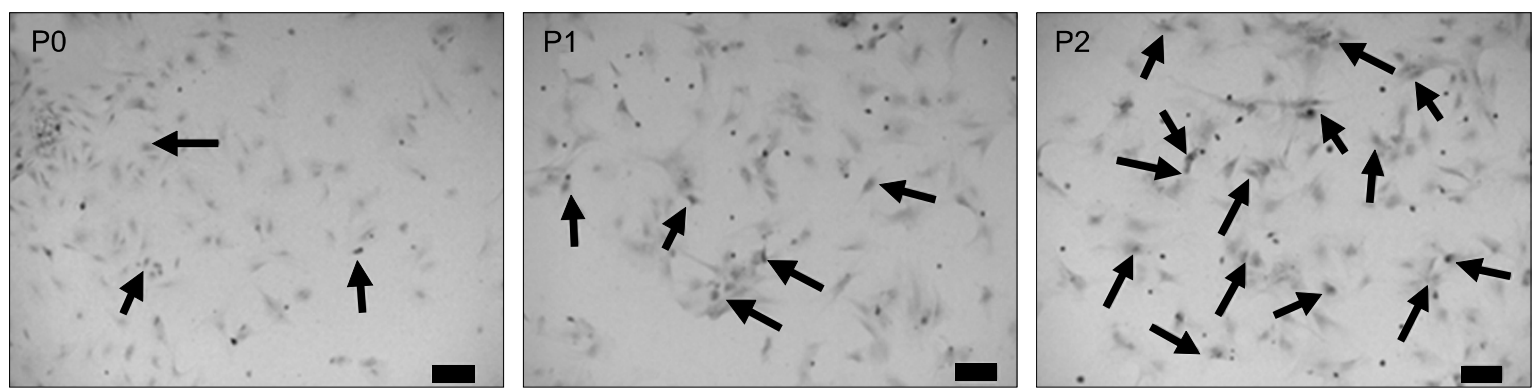

B
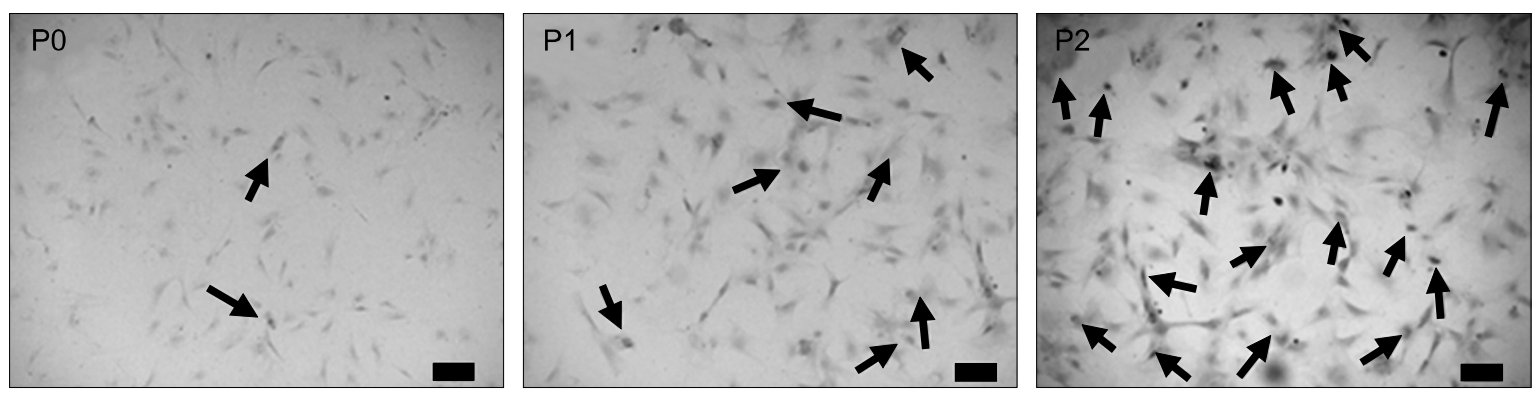

C

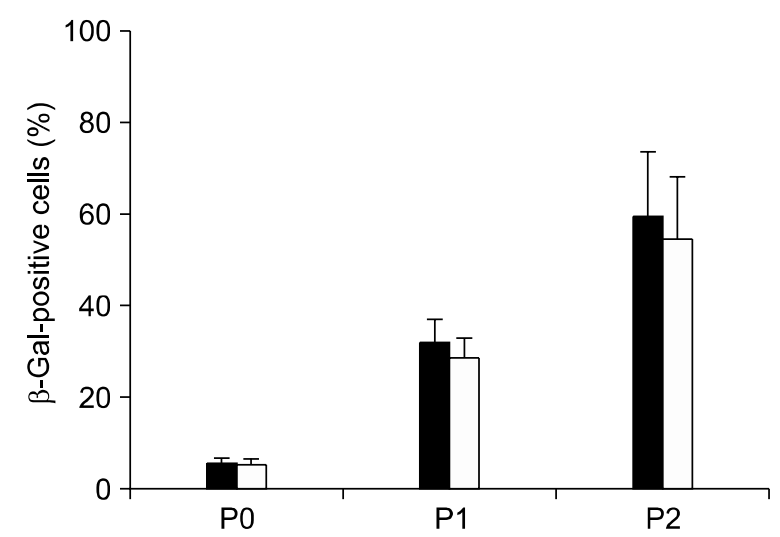

D

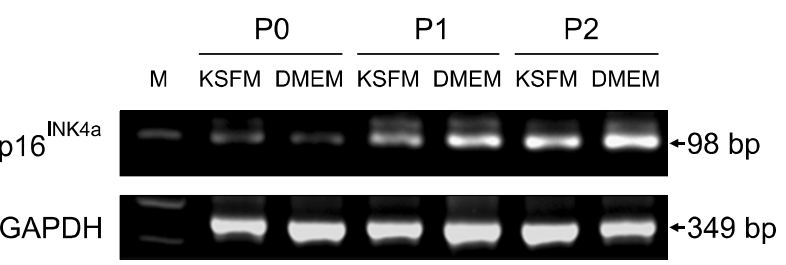

Figure 4. SA- $\beta$-gal staining of FKCs cultured in (A) DMEM and (B) KSFM. The blue color indicates a senescent cell. Arrows indicate SA- $\beta$-gal-positive cells. Scale bars indicate $50 \mu \mathrm{m}$. (C) Percent of SA- $\beta$-gal-positive cells in FKCs cultured in DMEM (solid bars) and KSFM (open bars). $P<0.05$ between any two groups. (D) mRNA expression levels of a senescence marker gene, p16 ${ }^{\text {IKK4a }}$, in cultured FKCs. M: 100 bp DNA molecular weight marker. 

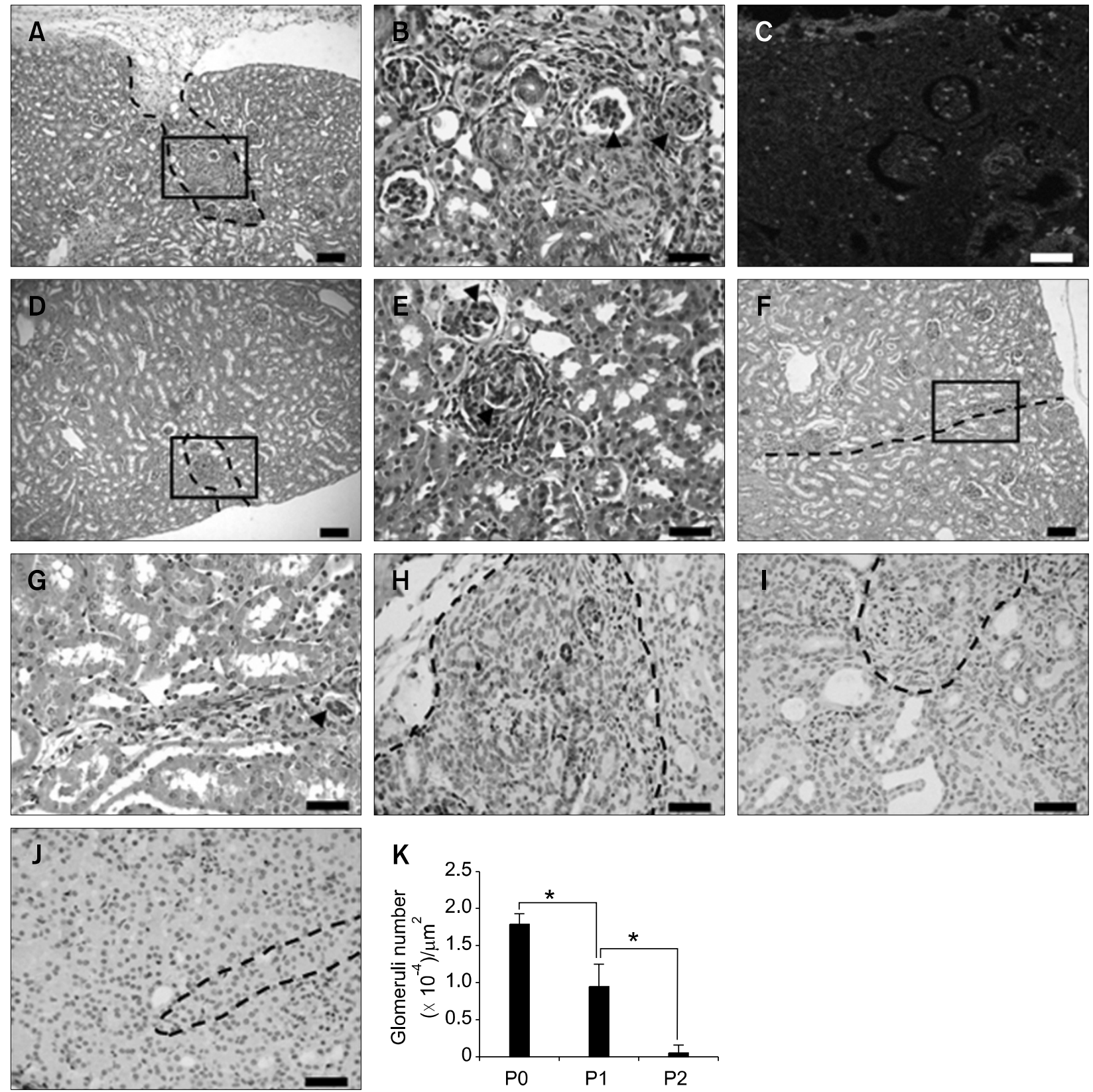

Figure 5. Histological micrographs of (A-C) P0, (D, E) P1, and (F, G) P2 transplants 4 wk after transplantation. Reconstituted glomeruli (solid arrowhead) and tubules (empty arrowhead) were observed in the transplants. (C) CM-Dil labeled FKCs were detected in the reconstituted regions. Scale bars indicate $50 \mu \mathrm{m}(\mathrm{A}, \mathrm{D}$, and $\mathrm{F})$ and $20 \mu \mathrm{m}(\mathrm{B}, \mathrm{C}, \mathrm{E}$, and G-J). Immunohistochemistry of reconstituted regions in (H) P0, (I) P1, and (J) P2 transplants for PCNA. (K) The average glomeruli numbers per unit area of the reconstituted region of each transplant. ${ }^{*} P<0.05$. Dotted lines indicate borders between native and reconstituted kidney structures. $B, E$, and $G$ are the higher magnifications of the lined areas in $A, D$, and $F$.

transplants, primitive kidney structures were also reconstituted, but the regeneration area was smaller than that of the P0 transplants (Figure 5D), and the reconstituted glomeruli and tubules were more primitive in structure (Figure 5E). P2 transplants showed very poor kidney structure regeneration (Figure 5F and $\mathrm{G}$ ). The average glomerulus number per unit area of the reconstituted region of each transplant was highest in the P0 transplants (Figure 5K). To investigate the fate of transplanted FKCs, FKCs were labeled with a red fluorescent dye, CM-Dil, prior to transplantation. Fluorescently labeled P0 FKCs were detected in the newlyformed kidney structures, indicating the presence of transplanted kidney precursor cells in the reconstituted kidney structures and their contribution to 
kidney reformation (Figure $5 \mathrm{C}$ ). Immunohistochemical analyses using antibodies against PCNA, a marker of proliferating cells, confirmed the intensive proliferating activity of the cells in the reconstituted regions of transplants. PCNA-positive cells were abundant in the transplants from PO cells (Figure $5 \mathrm{H}$ ) and $\mathrm{P} 1$ cells (Figure $5 \mathrm{I}$ ), compared with the transplants from P2 cells (Figure $5 \mathrm{~J}$ ).

\section{Discussion}

The goal of this study was to examine the effects of in vitro culture period on cellular characteristics of FKCs and on kidney tissue regeneration in vivo. As the passage number increased in both types of cultures, the growth rate of FKCs decreased and evidence of apoptosis and senescence increased. In addition, after the transplantation of cultured FKCs into live, functional kidneys, histological analyses of retrieved tissues showed passagedependent kidney tissue regeneration; the kidney regeneration was better when cells of lower passage number were transplanted. These observations show that the in vitro culture period of FKCs is a critical factor affecting the cell transplantation-mediated regeneration of kidney tissue.

In this study, transplantation of FKCs cultured for various in vitro culture periods resulted in the passage-dependent regeneration of kidney tissue in vivo. Successful organogenesis was achieved when cells with lower passage numbers were transplanted. As most of P2 cells were experiencing proliferative arrest and apoptosis, they showed poor in vivo regenerative capacity. The proliferative ability of cultured FKCs may affect the outcome of in vivo kidney tissue regeneration, because the engraftment and viability of transplanted cells might depend on the proliferative ability of the transplanted cells. Since senescent cells are incapable of self-renewal, it has been proposed that cellular senescence might cause or contribute to aging phenotypes, such as poor wound healing (Campisi, 2003). Poor wound healing is presumed to arise from a loss of cell proliferative, hence tissue regenerative, capacity (Hayflick and Moorhead, 1961).

The environmental stresses during in vitro primary culture periods may induce cultured FKCs to undergo senescence. In this study, senescence was notably observed in cultured FKCs as early as passage number two. Cell senescence is defined as a proliferative arrest that occurs in mammalian somatic cells after a limited number of cell divisions (Hayflick and Moorhead, 1961). When a cell reaches terminal growth arrest, it stops dividing but remains metabolically active for a time, so that it gradually fades away (Roninson, 2003). The fast appearance of cell senescence in this study might be due to the high susceptibility of fetal kidney cells to senescence likely caused by environmental stress (Blasco et al., 1997; Lee et al., 1998; Wright et al., 2000; Mathon et al., 2001; Tang et al., 2001). It has been reported that inadequate cell growth conditions may lead to premature growth arrest (Ramirez et al., 2001).

In summary, this study demonstrated that cultured FKCs showed decreased proliferative ability and increased apoptosis and senescence with increasing passage number. In addition, in vivo kidney tissue regeneration by transplantation of cultured FKCs is strongly dependent on the number of passages that the cells undergo. This study demonstrates the reconstitution of kidney tissues in vivo by transplanting FKCs and suggests that FKCs are a possible new cell source for kidney tissue engineering. While this study suggests that environmental stress contributes to the in vitro senescence phenotype of FKCs, the cause of environmental stresses and their roles in the aging of cultured cells remain to be clarified. In addition, culture conditions that minimize the cellular stress for FKCs should be investigated. With further understanding of these environmental stresses and related cell senescence, it could be possible to regenerate kidney tissue more efficiently from a small biopsy of kidney tissue. In addition, further information about the characteristics of FKCs will help elucidate how FKC transplantation can benefit kidney regeneration.

\section{Acknowledgement}

This work was supported by a grant (SC 3220) from the Stem Cell Research Center of the 21st Century Frontier Program, funded by the Ministry of Science and Technology, Republic of Korea.

\section{References}

Blasco MA, Lee HW, Hande MP, Samper E, Lansdorp PM, DePinho RA, Greider CW. Telomere shortening and tumor formation by mouse cells lacking telomerase RNA. Cell 1997; $91: 25-34$

Campisi J. Cellular senescence and apoptosis: how cellular responses might influence aging phenotypes. Exp Gerontol 2003;38:5-11

Dekel B, Burakova T, Arditti FD, Reich-Zeliger S, Milstein O, Aviel-Ronen S, Rechavi G, Friedman N, Kaminski N, Passwell JH, Reisner Y. Human and porcine early kidney precursors as a new source for transplantation. Nat Med 2003;9:53-60 
Deng W, Han Q, Liao L, Li C, Ge W, Zhao Z, You S, Deng H, Murad F, Zhao RC. Engrafted bone marrow-derived flk-(1+) mesenchymal stem cells regenerate skin tissue. Tissue Eng 2005; $11: 110-9$

Dimri GP, Lee X, Basile G, Acosta M, Scott G, Roskelley C, Medrano EE, Linskens M, Rubelj I, Pereira-Smith $O$, Peacocke M, Campisi J. A biomarker that identifies senescent human cells in culture and in aging skin in vivo. Proc Natl Acad Sci USA 1995;92:9363-7

Hammerman MR. Transplantation of renal precursor cells: a new therapeutic approach. Pediatr Nephrol 2000;14: 513-7

Hammerman MR. Treatment for end-stage renal disease: an organogenesis/tissue engineering odyssey. Transpl Immunol 2004; $12: 211-8$

Hayflick L, Moorhead PS. The serial cultivation of human diploid cell strains. Exp Cell Res 1961;25:585-621

Jeong SI, Kim BS, Kang SW, Kwon JH, Lee YM, Kim SH, Kim $\mathrm{YH}$. In vivo biocompatibilty and degradation behavior of elastic poly(L-lactide-co-epsilon-caprolactone) scaffolds. Biomaterials 2004;25:5939-46

Kim BS. Production of human hematopoietic progenitors in a clinical-scale stirred suspension bioreactor. Biotechnol Lett 1998;20:595-601

Kim SS, Park HJ, Han J, Park MS, Park MH, Song KW, Joo KJ, Choi CY, Kim BS. Renal precursor cell transplantation using biodegradable polymer scaffolds. J Microbiol Biotechnol 2005; $15: 105-11$

Kim SS, Lim SH, Cho SW, Gwak SJ, Hong YS, Chang BC, Park MH, Song KW, Choi CY, Kim BS. Tissue engineering of heart valves by recellularization of glutaraldehyde-fixed porcine valves using bone marrow-derived cells. Exp Mol Med 2006;38:273-83

Kim SS, Gwak SJ, Han J, Park HJ, Park MH, Song KW, Cho SW, Rhee YH, Chung HM, Kim BS. Kidney tissue reconstruction by fetal kidney cell transplantation: effect of gestation stage of fetal kidney cells. Stem Cells 2007a;25: 1393-401

Kim SS, Park HJ, Han J, Gwak SJ, Park MH, Song KW, Rhee $\mathrm{YH}$, Chung HM, Kim BS. Improvement of kidney failure with fetal kidney precursor cell transplantation. Transplantation

\section{7b;83:1249-58}

Lanza RP, Chung HY, Yoo JJ, Wettstein PJ, Blackwell C, Borson N, Hofmeister E, Schuch G, Soker S, Moraes CT, West MD, Atala A. Generation of histocompatible tissues using nuclear transplantation. Nat Biotechnol 2002;20: 689-96

Lee HW, Blasco MA, Gottlieb GJ, Horner JW, Greider CW, DePinho RA. Essential role of mouse telomerase in highly proliferative organs. Nature 1998;392:569-74

Mathon NF, Malcolm DS, Harrisingh MC, Cheng L, Lloyd AC. Lack of replicative senescence in normal rodent glia. Science 2001;291:872-5

Melk A, Kittikowit W, Sandhu I, Halloran KM, Grimm P, Schmidt BM, Halloran PF. Cell senescence in rat kidneys in vivo increases with growth and age despite lack of telomere shortening. Kidney Int 2003;63:2134-43

Ramirez RD, Morales CP, Herbert BS, Rohde JM, Passons C, Shay JW, Wright WE. Putative telomere-independent mechanisms of replicative aging reflect inadequate growth conditions. Genes Dev 2001;15:398-403

Roninson IB. Tumor cell senescence in cancer treatment, Cancer Res 2003;63:2705-15

Ryu JH, Kim IK, Cho SW, Cho MC, Hwang KK, Piao H, Piao S, Lim SH, Hong YS, Choi CY, Yoo KJ, Kim BS. Implantation of bone marrow mononuclear cells using injectable fibrin matrix enhances neovascularization in infarcted myocardium. Biomaterials 2005;26:319-26

Steer DL, Nigam SK. Developmental approaches to kidney tissue engineering. Am J Physiol Renal Physiol 2004; 286:F1-7

Tang DG, Tokumoto YM, Apperly JA, Lloyd AC, Raff MC. Lack of replicative senescence in cultured rat oligodendrocyte precursor cells. Science 2001;291:868-71

Wright WE, Shay JW. Telomere dynamics in cancer progression and prevention: fundamental differences in human and mouse telomere biology. Nat Med 2000;6: 849-51

Yoo JJ, Ashkar S, Atala A. Creation of functional kidney structures with excretion of urine-like fluid in vivo. Pediatrics 1996;98:S605 